Publisher: Taylor \& Francis

Journal: Expert Review of Hematology

DOI: $10.1080 / 17474086.2017 .1327809$

Review

Heme-mediated cell activation: the inflammatory puzzle of sickle cell anemia

Caroline Conceição da Guarda ${ }^{1}$, Rayra Pereira Santiago ${ }^{1}$, Luciana Magalhães Fiuza ${ }^{Y}$, Milena Magalhães Aleluia ${ }^{1}$, Júnia Raquel Dutra Ferreira ${ }^{1,2}$, Camylla Vilas Boas

Figueiredo $^{1}$, Setondji Cocou Modeste Alexandre Yahouedehou ${ }^{1}$, Rodrigo Mota de Oliveira $^{2}$, Isa Menezes Lyra ${ }^{3}$, Marilda de Souza Gonçalves*1,2

${ }^{1}$ Laboratório de Hematologia, Genética e Biologia Computacional, Instituto Gonçalo Moniz, FIOCRUZ, Salvador, Bahia

${ }^{2}$ Faculdade de Farmácia, Universidade Federal da Bahia, Salvador, Bahia

${ }^{3}$ Fundação de Hemoterapia e Hematologia do Estado da Bahia, Salvador, Bahia

*Corresponding author:

Marilda de Souza Gonçalyes,

Laboratório de Hematologia, Genética e Biologia Computacional, Instituto Gonçalo Moniz, Fundação Oswaldo Cruz (FIOCRUZ), Salvador, Bahia, Brasil, Rua

Valdemar Falcão, 121, Candeal, Salvador-BA-Brasil. Postal Code: 40.296-710.

Telephone: +55 (71) 3176-2226

E-mail:mari@bahia.fiocruz.br 


\begin{abstract}
Introduction: Hemolysis triggers the onset of several clinical manifestations of sickle cell anemia (SCA). During hemolysis, heme, which is derived from hemoglobin $(\mathrm{Hb})$, accumulates due to the inability of detoxification systems to scavenge sufficiently. Heme exerts multiple harmful effects, including leukocyte activation and migration, enhanced adhesion molecule expression by endothelial cells and the production of prooxidant molecules.

Area covered: In this review, we describe the effects of heme on leukocytes and endothelial cells, as well as the features of vascular endothelial cells related to vasoocclusion in SCA.

Expert commentary: Free $\mathrm{Hb}$, heme and iron, potent cytotoxic intravascular molecules released during hemolysis, can exacerbate, modulate and maintain the inflammatory response, a main feature of SCA. Endothelial cells in the vascular environment, as well as leukocytes, can become activated via the molecular signaling effects of heme. Due to the hemolytic nature of SCA, hemolysis represents an interesting therapeutic target for heme-scavenging purposes.
\end{abstract}

Keywords: Inflammation, heme, hemolysis, sickle cell anemia, sickle cell disease. 


\section{Sickle cell anemia}

Sickle cell anemia (SCA) was the first genetic disease in which an altered protein capable of causing clinical symptoms was verified. The underlying abnormality consists of a single nucleotide substitution (GAG $\rightarrow$ GTG), which replaces one amino acid $(\mathrm{Glu} \rightarrow \mathrm{Val})$ in the sixth position of the $\beta$ globin $\left(\beta^{6 \mathrm{Glu}-\mathrm{Val}}\right)$ amino terminal region. This produces the $\mathrm{Hb}$ variant $\mathrm{S}\left(\mathrm{HbS} ; \alpha_{2} \beta_{2}{ }^{\mathrm{S}}\right)$, forming long polymers when exposed to low oxygen concentrations $[1,2,3]$ which consequently provokes the deformation of erythrocytes that participate in the pathophysiological mechanism of SCA [4].

Sickling, the process in which polymers are assembled and erythrocytes suffer morphological changes, has been associated with three conditions: deoxygenation and alterations in both intracellular $\mathrm{HbS}$ and fetal $\mathrm{Hb}(\mathrm{HbF})$ concentrations. Changes in physicochemical properties, in addition to deformities and tensing of the erythrocyte membrane, are also responsible for the pathologic event of vaso-occlusion (VOC), since erythrocytes become predisposed to adhere to the vascular endothelium $[3,5]$. Repeated sickling cycles can cause severe injury to the erythrocyte membrane and generate reactive oxygen species (ROS). This process can also lead to an abnormal cation homeostasis, resulting in dehydrated, irreversibly sickled red blood cells, whose morphology tends to exacerbate the underlying hemolytic anemia and vascular obstructions seen in SCA [6].

Irreversibly sickled erythrocytes are usually removed from the bloodstream by the mononuclear phagocyte system, a phenomenon that shortens the erythrocyte lifespan from 120 days to nearly 31 days, thus contributing to SCA severity [7]. The removal of senescent red blood cells by macrophages in the spleen and liver (the mononuclear phagocyte system) is known as extravascular hemolysis, which is mainly regulated by the proteins responsible for heme degradation, e.g. heme oxygenase (HO1), and those involved in iron-metabolism, such as iron importer transferrin receptor 1 (TfR1), divalent metal transport 1 (DMT1), iron exporter ferroportin 1 (FPN1) and the iron regulatory hormone hepcidin [8]. This process does not usually elicit an 
inflammatory response, although it is believed that increased bacterial infection may result from functional asplenia, possibly due to recurrent ischemic accidents in the red pulp [9]. SCA patients present elevated vulnerability to chronic hemolysis and higher susceptibility to infection, in addition to VOC resulting in chronic ischemic injury to many organs, as well as endothelial dysfunction and early mortality [10].

SCA patients exhibit ongoing hemolysis even in the absence of an acute clinical hemolytic event. The pathologic mechanism of hemolysis leads to several complications, including renal, pulmonary and gastrointestinal manifestations, as well as priapism and leg ulcers [11]. It is accepted that hemolysis occurring in vascular spaces results in toxicity due to the release of free hemoglobin $(\mathrm{Hb})$, heme and arginase (which consumes arginine), resulting in clinical manifestations arising from systemic chronic oxidative stress and inflammation [12]. Our goal here is to review intravascular hemolysis in the context of SCA, paying particular attention to the inflammatory action of heme on vascular endothelial cells and leukocytes.

\section{SCA and endothelial cells in the vascular environment}

The endothelium represents the central hemostatic body regulator, essentially due to its ability to express pro-coagulant and anti-coagulant, vasoconstrictor and vasodilator agents, as well as adhesion molecules and cytokines [13]. The endothelium is inexorably linked to all homeostatic processes, as it interacts with both inflammatory and coagulation systems [14]. Under normal physiological conditions, endothelial cells maintain a fibrinolytic and vasodilator state, in which coagulation, platelet adhesion, inflammation and leukocyte activation are suppressed. The non-thrombogenic endothelial surface is sustained by a variety of mechanisms, including (i) the endothelial production of thrombomodulin and subsequent protein $\mathrm{C}$ activation; (ii) heparan sulfate and dermatan sulfate expression, which accelerates anti-thrombotic activity and heparin co-factor production; (iii) the constitutive expression of tissue factor pathway inhibitor; and (iv) the local production of tissue plasminogen activator and urokinase-like plasminogen activator. Furthermore, the production of nitric oxide (NO), prostacyclin and interleukin (IL)-10 also inhibit adhesion and the activation of leukocytes, resulting in vasodilatation $[13,15]$. 
On the other hand, it is known that vascular endothelial cell activation promotes the recruitment, activation and adhesion of circulating leukocytes, which results in abnormal adhesive interactions among erythrocytes, leukocytes and endothelial cells [4, 16]. Endothelial cells express adhesion molecules and produce other chemotactic factors when challenged with inflammatory stimuli. In SCA, these stimuli can be of multiple origin: cytokines, lipid mediators, irreversibly sickled erythrocytes, platelets, and even heme released from hemolytic events $[14,17,18]$.

SCA patients exhibit a chronically inflamed microvascular environment that participates in the onset of clinical symptoms, including pulmonary hypertension, leg ulcers and priapism $[19,20]$. This persistent inflammatory response may occur due to the failure or inefficiency of the mechanisms usually responsible for the maintenance of homeostasis [21]. A chronic pro-inflammatory state is exacerbated by increased cytokine levels, such as interleukin (IL)-1, tumor necrosis factor- alpha (TNF- $\alpha$ ), endothelin-1 and granulocyte macrophage colony-stimulating factor (GMCSF), produced by activated endothelial cells and monocytes $[6,22,23]$. It has recently been suggested that the microvascular milieu may also be activated by other molecules, such as transforming growth factor beta 1 (TGF- $\beta$ ), IL-17 and IL-18, opening new lines of investigation into novel inflammatory pathways in SCA [24, 25]. These biological mediators are known to be systemically elevated in SCA patients during acute pain crisis or VOC, as well as those in in steady-state [14].

In SCA, the endothelium and subendothelial structures suffer alterations due to the presence of circulating endothelial cells $[4,26]$. Leukocytes, red blood cells and the vascular endothelium interact through the expression of adhesion molecules by heterogeneous multicellular aggregate that may give rise to VOC. Some endothelial proteins become involved in abnormal adhesiveness, e.g. intercellular adhesion molecule-1 (ICAM-1), vascular cell adhesion molecule-1 (VCAM-1), E-selectin, Pselectin, laminin, thrombospondin, fibronectin and $\alpha_{V} \beta_{3}$ integrin, which each bind to specific corresponding receptors in leukocytes and erythrocytes. Even in asymptomatic patients, soluble forms of VCAM-1, ICAM-1, P-selectin, laminin and thrombospondin remain elevated [16]. In a murine model of SCA employing knockout for P- and Eselectin in endothelial cells, fewer leukocytes became activated and VOC decreased, corroborating the suggested role of adhesion molecules in the physiopathology of this disease $[27,28]$. Importantly, a recent clinical trial involving sickle cell disease (SCD) patients showed that an antibody against P-selectin was able to decrease the median 
annual rate of pain crises, in addition to extending the average interval between crisis episodes [29]. Integrin $\alpha_{4} \beta_{1}$ (Very late antigen-4; VLA-4) and CD36 (thrombospondin receptor), the first adhesion molecules identified in erythrocytes [30, 31, 32], become overexpressed by reticulocytes under anemic stress [33].

Sickle erythrocytes exhibit greater adherence to the vascular endothelium than unaltered cells. Many receptors mediate this adherence, such as basal cell adhesion molecule (BCAM, CD239), CD47, CD147, intercellular adhesion molecule-4 (ICAM4) and phosphatidylserine. In normal erythrocytes, phosphatidylserine is usually found on the inner cell membrane surface $[4,32,33]$. The adherence of sickle erythrocytes to the endothelium is not an isolated process, since it can also initiate the production of ROS in association with the activation of nuclear factor- $\kappa \mathrm{B}(\mathrm{NF}-\kappa \mathrm{B})$, which contributes to chronic vascular activation [6] (Figure 1). Accordingly, it is possible that more than one mechanism is involved in the cellular adhesion process seen in SCA. It follows that the mechanisms underlying adhesion may differ not only among patients, but also among the organs affected, over time, or even among different types of blood vessels [14].

Intravascular hemolysis promotes the release of arginase from the erythrocytes that consume arginine, the main substrate by which endothelial cells produce NO through the endothelial isoform of nitric oxide synthase (eNOS). Cell-free $\mathrm{Hb}$ also reacts rapidly with $\mathrm{NO}$, enhancing the production of nitrate, methemoglobin and ironnitrosyl hemoglobin. Decreased NO bioavailability is a main characteristic of endothelial dysfunction, reducing vasodilatation while causing endothelial activation and proliferation. SCA patients exhibit a chronic deficiency of NO, which exacerbates VOC and hemolysis [5, 34, 35, 36]. Vasculopathy in association with endothelial dysfunction represent the most important chronic alterations ascribed to SCA, due to active participation in severe clinical manifestations, including stroke, renal disease and pulmonary hypertension. The pathophysiology of SCA is closely related to hemolysis and vascular endothelial dysfunction, although many other interrelated processes can be considered equally important [37]. Hemolysis and loss of splenic function, both frequent occurrences in SCA, have been associated with injury to the erythrocyte membrane, as well as the translocation of phosphatidylserine and activation of tissue factor (TF) and thrombosis factor [5], which contribute to the hemostatic alterations described in this disease. TF is a cell receptor for factor VII/VIIa, a physiological initiator of the coagulation cascade. TF forms a complex with circulating FVIIa, which 
then activates factor $\mathrm{X}$ with subsequent thrombin formation. Although $\mathrm{TF}$ is not constitutively expressed in vivo in the endothelium or in monocytes, its expression can be induced by many relevant pathophysiological agonists derived from hemolytic anemia, such as the pro-inflammatory cytokines IL-1 and TNF- $\alpha$, hypoxia, shear stress, growth factors, endotoxins and ischemia-reperfusion injury [18, 38, 39, 40].

Chronic anemia and tissue ischemia can also contribute to proliferative vasculopathy by activating the transcription factor hypoxia-inducible factor 1-alpha (HIF-1 $\alpha$ ). This leads to increased expression of the nitric oxide synthase-2 (NOS2A) gene, which encodes inducible nitric oxide synthase (iNOS), in addition to erythropoietin and vascular endothelial growth factor (VEGF) [5]. The enzymatic action of NOS generates NO via the conversion of L-arginine to L-citrulline [41]. Its endothelial isoform (eNOS) is constitutively expressed and activated by way of increased intracellular calcium [42, 43].

Hypoxia-inducible factors (HIF-1 $\alpha$, HIF-1 $\beta$ and HIF-2 $\alpha$ ) are known to influence vascular gene transcription. The expression and activity of the HIF-1 $\alpha$ subunit that forms heterodimers with HIF-1 $\beta$ are regulated by cellular $\mathrm{O}_{2}$ concentration. Under hypoxia conditions, HIF-1 $\alpha$ can activate the transcription of genes, such as erythropoietin, glucose transporters, glycolytic enzymes, VEGF and its receptors (VEGFR1 and VEGFR2), in addition to other genes whose proteins are responsible for increasing $\mathrm{O}_{2}$ bioavailability and supporting metabolic adaptation to hypoxia. HIF-1 $\alpha$ also induces the expression of genes involved in vascular tonus, cellular growth and inflammation $[44,45]$. In cancer cells, it has been shown that HIF-1 $\alpha$ can induce the expression of genes involved in iron metabolism, thereby contributing to iron accumulation. Accordingly, HIF-1 $\alpha$ can induce the expression of Transferrin receptor-1 (TrR1), resulting in elevated iron internalization [46, 47]. Importantly, HIF-1 $\alpha$ also induces the expression of heme-oxygenase (HO-1) which promotes heme degradation and releases carbon monoxide and biliverdin, promoting iron recycling [48, 49]. Endothelial cell activation reportedly occurs via hemolytic products, including heme [17]. Since the receptor for hemopexin (Hpx), a glycoprotein that binds to heme, is not expressed by endothelial cells, extracellular internalization becomes impossible in SCA due to the abundance of free heme, making the endothelium vulnerable to heme toxicity $[12,50]$. A growing body of evidence has suggested that in addition to, or even prior to, direct cellular interaction and the sickling process, molecular inflammatory mechanisms 
driven by hemolytic molecules may play a fundamental role in the pathophysiology of SCA. 


\section{Vaso-occlusion}

Irreversibly sickled erythrocytes play a critical role not only in VOC, but also in many other complications described in SCA [51]. The deformation of erythrocytes is a downstream effect of recurrent cycles of $\mathrm{HbS}$ polymerization, and the systemic chronic inflammatory status of SCA individuals in association with endothelial dysfunction increases oxidative stress and cellular adhesion via a complex process involving many steps, together with the participation of a variety of cell types [52].

VOC, regardless of its primary cause, contributes to tissue ischemia and endothelial dysfunction, thereby enhancing inflammatory status. In addition, inflammation can also influence the onset of VOC [14]. Currently, it is known that vascular endothelial cells directly participate in the development and propagation of VOC, which is driven by multiple cell interactions and extensive cellular activation mediated by the inflammatory process $[4,53]$ (Figure 2 ).

The phenomenon of VOC appears to be a complex process, beginning with increased reticulocyte production. These cells become more adherent to post-capillary endothelial venules in response to hemolysis, slowing blood flow and creating vascular stasis. This induces and propagates the sickling process as erythrocytes are maintained for extended periods under hypoxia conditions, leading to the increased capture of sickle erythrocytes and other blood cells in the micro-vascular environment $[4,53]$. Although it is not completely known which occurs first, i.e. inflammation or VOC, many researchers believe that both phenomena may actually occur simultaneously, resulting in a repetitive, interdependent cycle [54].

$\mathrm{HbS}$ polymerization promotes the destabilization of the erythrocyte membrane, leading to the premature destruction of $10 \%$ of total erythrocytes every 24 hours, equivalent to the release of up to $30 \mathrm{~g}$ of $\mathrm{Hb}$ per day [36]. Auto-oxidation of $\mathrm{Hb}$ and the subsequent release of the heme group occur faster from $\mathrm{HbS}$ than from normal $\mathrm{Hb}$ $(\mathrm{HbA})$. In addition, the pathologic properties of free heme with respect to the oxidation of cellular membranes have been described in SCA $[36,55]$. Cell-free $\mathrm{Hb}$, delivered secondarily during hemolysis in SCA, is sufficient, even at concentrations as low as $6 \mu \mathrm{M}$, to neutralize NO-induced vasodilatation $[36,56]$ and negatively modulate the hemostatic equilibrium. Heme is one of the molecules capable of inducing endothelial cell stimulation and causing damage to the endothelium, thereby promoting the recruitment of neutrophils and sickle erythrocytes, which prompts VOC [57]. The two 
main pathophysiologic features of SCA are hemolysis and VOC. The painful crises experienced by individuals with SCA frequently arise from the pathophysiological events precipitating VOC, in association with the presence of chronic hemolytic anemia and hyper hemolysis $[11,12]$. Due to the hemolytic anemia feature of SCA, the role of inflammation driven by intravascular hemolysis in SCA context is important. This cascade of events indicates the importance of the primary pathological aspect $(\mathrm{HbS}$ polymerization), which leads to the leakage of intraerythrocytic components into the vascular environment (i.e. hemolysis), inducing an inflammatory response driven by leukocytes and the endothelial activation caused by heme.

\section{Heme and inflammation}

The heme molecule is composed of iron and protoporphyrin IX, which consists of four pirrolic rings linked by "-CH" groups [58]. Under normal physiological conditions, heme is either sequestered intracellularly or is tightly bound to the polypeptide chains of different hemeproteins $[59,60]$. Heme is present in a reduced state within red blood cells for oxygen binding purposes. When a red blood cell is lysed, heme is released and ferro- $\mathrm{O}_{2} \mathrm{Hb}$ is bound by haptoglobin ( $\left.\mathrm{Hp}\right)$, resulting in the mounting of ferric-Hb-Hp. The CD163 receptor mediates the endocytosis of $\mathrm{Hb}-\mathrm{Hp}$ complexes, and is expressed by a variety of cell types, such as mature tissue macrophages, i.e. those present in the spleen, liver, lymph nodes, bone marrow, lungs, placenta, peritoneum, thymus and Kuppfer cells [12]. The clearance of $\mathrm{Hp}-\mathrm{Hb}$ complexes is impaired when Hp and Hpx are depleted under pathologic conditions, such as extensive hemolysis in SCA. A recent report described decreased levels of Hp and $\mathrm{Hpx}$ in SCA patients, as well as reduced $\mathrm{Hb}$ and hematocrit in comparison to healthy volunteers, while lactate dehydrogenase (LDH) and reticulocyte counts were increased [61]. In addition, while heme may also bind to human serum albumin, the heme molecules that do not bind to proteins are able to move across the plasma membrane and potentially interact with low density lipoprotein (LDL) $[12,60]$.

During intravascular hemolysis, free $\mathrm{Hb}$ reacts and degrades $\mathrm{NO}$, while arginase consumes L-arginine and reduces NO bioavailability. Cell-free $\mathrm{Hb}$ can also release its heme prosthetic groups, allowing free heme to exhibit harmful effects due to its ability to catalyze reactive oxidative species (ROS) production, which results in cellular 
dysfunction or injury [51]. All the events that culminate in ROS production end up leading to vasoconstriction in SCA [36].

Each type of body tissue responds differently to hemolysis. These responses rely on tissue-specific properties, such as differential distribution of vascular beds, vascular endothelial cell heterogeneity, intravascular hemolysis intensity, cytokine, Hp and Hpx levels, heme oxygenase activity and $\mathrm{O}_{2}$ concentration [17]. In SCA, the quantities of $\mathrm{Hp}$ and Hpx are insufficient to bind to the large quantity of free $\mathrm{Hb}$ and heme, which, in addition to the subclinical hemolytic process, are responsible for the maintenance of the vascular pro-inflammatory and pro-oxidant milieu. When large amounts of free heme or hemeproteins accumulate, detoxification systems become overwhelmed, making it likely that heme will exert deleterious effects [58].

Iron overload, as well as infection, can contribute to the biology of inflammation in SCA [14, 17]. The high heme concentrations seen in the membranes of sickle erythrocytes are correlated with the reduced lifespan of erythrocytes, as well as with disease severity [62]. In addition, high heme plasmatic concentrations have been associated with VOC and acute chest syndrome in SCD children [63]. A report involving SCD patients indicated that iron-regulated genes are differentially expressed when compared to healthy volunteers [64]. The overexpression of such genes was associated with inflammation and innate immune response, since toll-like receptor 4 (TLR4) and IL-6 gene expression were observed. Genetic evidence also suggested an association between intracellular iron accumulation caused by a Ferroportin Q248H polymorphism and increased levels of IL-6 and C reactive protein (CRP), an important acute phase reactant, which has been independently associated with early death [64]. This finding is important to reinforce previous in vitro studies assessing the role of TLR, because intracellular iron promotes inflammatory pathways related to innate immune response.

The underlying mechanism responsible for free heme cytotoxicity is based on its highly hydrophobic property, which allows the iron contained within its protoporphyrin IX ring to enter and cross cell membranes, in addition to other lipid structures [58]. Additionally, heme-trafficking protein importers, such as Feline leukemia virus sub group C receptor 2 (FLVCR2), and the heme carrier protein1/Proton-coupled folate transporter (HCP1/PCFT), in addition to exporters, such as Feline leukemia virus sub group C receptor 1a (FLVCR1a) and ATP-binding cassette, sub-family G, member 2 (ABCG2), have also been shown to play an important role in heme transport $[65,66]$. 
Although iron represents an essential cellular element, since it plays an important role in a wide range of biochemical and metabolic reactions, its highly unstable nature is essential to the ability of heme to produce ROS and promote inflammation. Iron released from the protoporphyrin IX ring can act as a potent pro-oxidant mediator, since it can donate electrons which foster the generation of ROS through the Fenton reaction [67]. Both erythrocyte clearance and extracellular $\mathrm{Hb}$ scavenging are mild events under normal physiological conditions, but these become dramatically exacerbated in hemolytic disorders such as SCA [17]. Besides increasing levels of cell-free $\mathrm{Hb}$, hemolysis and oxidative stress also contribute to decreased NO bioavailability in SCA. Superoxide $\left(\mathrm{O}_{2}^{-}\right)$can be generated during the Fenton reaction and can react with NO to form peroxynitrite $\left(\mathrm{ONOO}^{-}\right)$and peroxynitrous acid, which further limits NO bioavailability and may favor vasoconstriction [68, 69].

Heme exhibits many proinflammatory properties, such as leukocyte activation and migration, increased expression of adhesion molecules and the induction of acutephase protein production $[70,71,72]$. Cellular activation is a pivotal step in the inflammatory process, leading to cytokine, chemokine, lipid mediator and ROS production. Different cell types participate in the inflammatory response to SCA, notably leukocytes, erythrocytes, platelets and vascular endothelial cells. Moreover, it is known that intravascular hemolysis molecules also promote inflammatory reactions from these cells [54]. It has been suggested that heme activates tissue macrophages to produce leukotriene B4 (LTB4), an important lipid mediator capable of increasing neutrophil chemotaxis [73]. It was also suggested that heme could act directly on neutrophils by delaying apoptosis [74], which could prove detrimental in SCA due to the maintenance of inflammation. Interaction between heme and neutrophils also leads to the reorganization of the cytoskeleton, ROS production through $\mathrm{C}$ protein kinase and increased interleukin (IL)-8 production $[71,74]$. The association of heme with the innate immune system through a receptor-mediated mechanism has been previously demonstrated [70] and is based on its ability to bind to TLR4, which unveiled a new pathway of modulation regarding inflammatory response. The family of TLR receptors are pattern-recognition receptors (PRRs) which recognize pathogen associated molecular patterns (PAMPs) from microorganisms or danger-associated molecular patterns (DAMPs) from damaged tissue [75]. Since the innate immune response is involved in systemic responses, the role of heme as an agonist of TLR4 may suggest that endogenous molecules from damaged cells, such as heme released from red blood 
cells during hemolysis, may be responsible for the triggering, amplification or perpetuation of the inflammatory response in SCA. It has been proposed that heme is able to induce necrosis in murine peritoneal macrophages via the TLR4/Myd88 pathway, with increased TNF expression, in addition heme is also able to enhance ROS production in a TLR4-independent pathway. [76]. Heme's ability to bind to these receptors highlights its role in the inflammatory process and in the chronic inflammatory status seen in SCA. Moreover, heme also influences the inflammatory process through the activation of the protein platform inflammasome. It has been recently observed that intravascular hemolysis can activate the NOD-like receptor family pyrin domain containing 3 (NLRP3) inflammasome in vitro, leading to subsequent IL-1 beta $(\beta)$ production by peritoneal macrophages $[67]$. The recognition by NLRP3 of hemolysis molecules and erythroid components as DAMPs reinforces the role played by the innate immune response in promoting the chronic inflammatory status seen in SCA [77].

In addition to leukocyte activation, heme is also able to activate cells in the vascular endothelium, provoking inflammation, as evidenced by the increased expression of adhesion molecules, including ICAM-1, and VCAM-1 and E-selectin [72]. It is important to highlight that in addition to this classical form of endothelial activation through the enhanced expression of adhesion molecules, heme is also able to bind to TLR4 in endothelial cells. This results in the activation of NF-kB, the mobilization of Weibel-Palade corpuscles and increases in von Willebrand factor and Pselectin production [17]. Similar to what was observed with leukocytes, heme is also a potent agonist of innate immune response receptors and has been considered an importantDAMP on SCA inflammation. Heme can also trigger the extrinsic pathway of coagulation by upregulating TF on the surface of endothelial cells in vitro [18]. An in vitro investigation suggested that heme is capable of increasing HIF-1 $\alpha$, eNOS and nitric oxide metabolite production by endothelial cells [78]. Notably, heme-bound iron is able to activate the expression of placenta growth factor (PIG), an important angiogenic factor, in a dose- and time-dependent manner in both murine and human erythroid cells via the EKLF pathway [79].

Heme, when released from methemoglobin (metHb), can also catalyze the oxidation of LDL, which induces endothelial cytolysis as a result of lipid hydroperoxide activity. Heme can be spontaneously inserted into LDL particles, leading to oxidative alterations in LDL that prove highly cytotoxic to endothelial cells. To defend against 
these cytotoxic effects, endothelial cells increase the production of heme-recycling enzymes, such as hemoxygenase-1 and ferritin [60]. In addition, in SCD, elevated levels of erythrocyte membrane microparticles can also transport heme, thereby contributing to increased oxidative stress, vascular dysfunction and VOC [80]. A summary of the effects of heme on several cell types is depicted in Figure 3.

\section{Conclusion}

SCA is an inherited hemolytic disease of complex pathophysiology that induces a wide range of clinical manifestations. During the hemolysis seen in SCA, several proinflammatory molecules are released from red blood cells, including $\mathrm{Hb}$, heme, iron and arginase, which are responsible for ongoing inflammation. Interaction between heme and innate immune receptors in both leukocytes and vascular endothelial cells increases the expression of adhesion molecules, thereby exacerbating oxidative stress and modulating cytokine production. Thus, it is of crucial importance to comprehensively investigate the inflammatory response driven by heme, especially in light of its ability to act as an endogenous damage-associated molecular pattern agonist, and attempt to elucidate the underlying mechanisms responsible for the chronic inflammatory process exhibited by SCA patients,

\section{Expert commentary}

SCA is characterized by persistent hemolysis, which overwhelms the body's detoxification systems and results in the accumulation of heme, leading to excessive oxidative stress, NO depletion and chronic inflammation. Heme's inflammatory effects arise from the molecule's structure, as well as from its ability to activate several cell types. Elevated heme concentrations in the membranes of sickle erythrocytes have been associated with SCA disease severity and clinical manifestations, including VOC and acute chest syndrome [63]; accordingly, episodes of painful crisis may be related to the events that lead to VOC in association with a chronic hemolytic anemia status. Numerous laboratory parameter can be assessed to evaluate the extent of hemolysis, aiding in the monitoring of the patient's clinical course. Biochemical markers such as $\mathrm{LDH}$, bilirubin levels, alanine and aspartate aminotransferase levels, as well as $\mathrm{Hb}$ and 
Hp levels, may prove useful; however, these do not correlate with markers designed to quantify the rate of hemolysis [7]. A recent report has shown that absolute reticulocyte counts may provide a better approach to evaluate hemolysis, due to this cell's strong correlation with red blood cell lifespan [7]. Importantly, although these laboratory parameters are accessible, the only pharmacological treatment (hydroxyurea) available increases $\mathrm{HbF}$ levels, while also decreasing leukocyte counts, which leads to an improved clinical prognosis [81]. The biological relevance of hemolysis derives from in vitro studies [17, 77] and also from patient evaluations [82]. A hemolytic subphenotype has even been proposed [19], but its specific pathologic role and contribution to clinical manifestations remains unclear. In sum, given the relevance of hemolysis and the toxic effects arising from this process, the development of new therapeutic approaches that aim to improve the hemolytic profile is necessary. Since free heme can act as an endogenous danger signal that promotes significant pro-inflammatory activity, heme scavenging may be a potent therapeutic approach to prevent tissue damage, inflammation and VOC. Due to heme's ability to trigger vascular and organ dysfunction, therapies designed to increase $\mathrm{Hb}$ and heme scavenging may prove useful. $\mathrm{The} \mathrm{Hb}$ and heme scavenger proteins $\mathrm{Hp}$ and Hpx have been evaluated as options to treat diseases, such as hemolytic transfusion reaction, ABO-incompatible bone marrow transplantation and other clinical conditions [83]. Hpx has been examined in mouse models of SCD in order to improve the inflammatory response and vaso-occlusion [84], as well as to block the vascular dysfunction caused by red blood cell microparticles laden with heme [80]. Progress towards furthering the understanding of the hemolytic process is further challenged by the complexity of the molecules involved and the underlying inflammation exhibited by SCA patients. Likewise, alternative therapies represent a new field of investigation in an attempt to mitigate the effects of hemolysis and inflammation. 


\section{Five-year view}

The current knowledge about hemolysis and inflammatory response in SCA is derived from in vitro studies as well as from patients' evaluation. Previous studies suggest that SCA may be dichotomized in two subphenotypes with specific clinical manifestations and laboratory characteristics, with a polarization of a hemolytic or endothelial dysfunction response, although the subphenotypes often overlap. In addition, hemolysis is the focus of the latest research regarding SCA and more recent reports suggest the role of hemolysis as an initiator to endothelial cell activation. In five years, a more comprehensive understanding of hemolysis, as well as the leukocyte and endothelial cell activation driven by heme in SCA, may come to tight. The immunemediated mechanism involving heme and TLR4 is relevant and seems to play an important role in the pathway of endothelial and monocytes activation, which contributes to VOC. However, experimental data may identify novel receptors for heme in different cell types in addition to receptors for hemolysis-derived molecules leading to new pathways of cellular activation. Likewise, epidemiologic studies assessing mortality risks in association to hemolysis intensity will corroborate the known pathophysiologic mechanisms, which lead to the clinical manifestations. Studies seeking to investigate different pathways of inflammation, along with the clarification of the complex regulatory network characterized by oxidative stress, adhesion molecule expression and leukocyte activation mediated by heme are essential to lead to the development of new therapeutic targets, and should yield greater insight into the molecules involved in the chronic inflammatory response exhibited by SCA patients.

\section{Key-issues}

- Hemolysis plays an important role in the pathophysiological mechanism underlying SCA, perpetuating the inflammatory response.

- It is becoming more evident that the inflammatory response elicited by heme and several hemolysis molecules arises from an association with the innate immune response. 
- The activation of leukocytes and the vascular endothelium mediated by heme represent potential therapeutic targets that may hold promise in minimizing the adverse effects brought on by hemolysis.

\section{Funding}

This manuscript was not funded.

\section{Declaration of interest}

The authors have no relevant affiliations or financial involvement with any organization or entity with a financial interest in or financial conflict with the subject matter or materials discussed in the manuscript. This includes employment, consultancies, honoraria, stock ownership or options, expert testimony, grants or patents received or pending, or royalties.

\section{Acknowledgments}

We would like to thank to Andris K. Walter for English language revision and manuscript copyediting assistance. 


\section{References}

Reference annotations

* Of interest

** Of considerable interest

1. Ingram VM. A specific chemical difference between the globins of normal human and sickle-cell anaemia haemoglobin. Nature. 1956;178:792-4. Epub 1956/10/13.

2. Pauling L, Itano $\mathrm{HA}$, et al. Sickle cell anemia, a molecular disease. Science. 1949;109:443. Epub 1949/04/29.

3. Steinberg MH. Management of sickle cell disease. The New England journal of medicine. 1999;340:1021-30. Epub 1999/04/01.

4. Odievre $\mathrm{MH}$, Verger E, Silva-Pinto AC, Elion J. Pathophysiological insights in sickle cell disease. The Indian journal of medical research. 2011;134:532-7. Epub 2011/11/18.

5. Steinberg MH. Sickle cell anemia, the first molecular disease: overview of molecular etiology, pathophysiology, and therapeutic approaches. TheScientifjcWorldJournal. 2008;8:1295-324. Epub 2008/12/30.

6. Chiang EY, Frenette PS. Sickle cell vaso-occlusion. Hematology/oncology clinics of North America. 2005;19:771-84, v. Epub 2005/10/11.

7. Quinn CT, Smith EP, Arbabi S, Khera PK, Lindsell CJ, Niss O, Joiner CH, Franco RS, Cohen RM. Biochemical surrogate markers of hemolysis do not correlate with directly measured erythrocyte survival in sickle cell anemia. American journal of hematology. 2016;91:1195-201. Epub 2016/09/21.

8. Kong $\mathrm{W}-\mathrm{N}$, Lei $\mathrm{Y}-\mathrm{H}$, Chang $\mathrm{Y}-\mathrm{Z}$. The regulation of iron metabolism in the mononuclear phagocyte system. Expert review of hematology. 2013;6:411-8.

9. Pizzi M, Fuligni F, Santoro L, Sabattini E, Ichino M, De Vito R, Zucchetta P, Colombatti R, Sainati L, Gamba P, Alaggio R. Spleen histology in children with sickle cell disease and hereditary spherocytosis: hints on the disease pathophysiology. Human pathology. 2017;60:95-103. Epub 2016/10/25.

10. Nebor D, Broquere C, Brudey K, Mougenel D, Tarer V, Connes P, Elion J, Romana M. Alpha-thalassemia is associated with a decreased occurrence and a delayed age-at-onset of albuminuria in sickle cell anemia patients. Blood cells, molecules \& diseases. 2010;45:154-8. Epub 2010/07/06.

11. Taylor JGt, Nolan VG, Mendelsohn L, Kato GJ, Gladwin MT, Steinberg MH. Chronic hyper-hemolysis in sickle cell anemia: association of vascular complications and mortality with less frequent vasoocclusive pain. PloS one. 2008;3:e2095. Epub 2008/05/08.

12. Smith A, McCulloh RJ. Hemopexin and haptoglobin: allies against heme toxicity from hemoglobin not contenders. Frontiers in physiology. 2015;6:187. Epub 2015/07/16.

13. Wakefield TW, Myers DD, Henke PK. Mechanisms of venous thrombosis and resolution. Arteriosclerosis, thrombosis, and vascular biology. 2008;28:387-91. Epub 2008/02/26.

14. Hebbel RP, Osarogiagbon R, Kaul D. The endothelial biology of sickle cell disease: inflammation and a chronic vasculopathy. Microcirculation. 2004;11:129-51. Epub 2004/07/29. 15. Becker BF, Heindl B, Kupatt C, Zahler S. Endothelial function and hemostasis. Zeitschrift fur Kardiologie. 2000;89:160-7. Epub 2000/05/08.

16. Johnson C, Telen MJ. Adhesion molecules and hydroxyurea in the pathophysiology of sickle cell disease. Haematologica. 2008;93:481-5. Epub 2008/04/02.

17. Belcher JD, Chen C, Nguyen J, Milbauer L, Abdulla F, Alayash Al, Smith A, Nath KA, Hebbel RP, Vercellotti GM. Heme triggers TLR4 signaling leading to endothelial cell activation and vaso-occlusion in murine sickle cell disease. Blood. 2014;123:377-90. Epub 2013/11/28. 
*Important due to the extensive characterization of the effects of heme in the vascular endothelial cells as well as the expressive role of TLR4 as a receptor for heme.

18. Setty BN, Betal SG, Zhang J, Stuart MJ. Heme induces endothelial tissue factor expression: potential role in hemostatic activation in patients with hemolytic anemia. Journal of thrombosis and haemostasis : JTH. 2008;6:2202-9. Epub 2008/11/06.

19. Kato GJ, Gladwin MT, Steinberg MH. Deconstructing sickle cell disease: reappraisal of the role of hemolysis in the development of clinical subphenotypes. Blood reviews. 2007;21:37-47. Epub 2006/11/07.

20. Nolan VG, Adewoye A, Baldwin C, Wang L, Ma Q, Wyszynski DF, Farrell JJ, Sebastiani P, Farrer LA, Steinberg MH. Sickle cell leg ulcers: associations with haemolysis and SNPs in Klotho, TEK and genes of the TGF-beta/BMP pathway. British journal of haematology. 2006;133:570-8. Epub 2006/05/10.

21. Conran N, Almeida CB, Lanaro C, Ferreira RP, Traina F, Saad ST, Costa FF. Inhibition of caspase-dependent spontaneous apoptosis via a cAMP-protein kinase A dependent pathway in neutrophils from sickle cell disease patients. British journal of haematology. 2007;139:148-58. Epub 2007/08/23.

22. Croizat H. Circulating cytokines in sickle cell patients during steady state. British journal of haematology. 1994;87:592-7. Epub 1994/07/01.

23. Francis RB, Jr., Haywood LJ. Elevated immunoreactive tumor necrosis factor and interleukin-1 in sickle cell disease. Journal of the National Medical Association. 1992;84:611-5. Epub 1992/07/11.

24. Cerqueira BA, Boas WV, Zanette AD, Reis MG, Goncalves MS. Increased concentrations of IL-18 and uric acid in sickle cell anemia: contribution of hemolysis, endothelial activation and the inflammasome. Cytokine. 2011;56:471-6. Epub 2011/08/30.

25. Vilas-Boas W, Veloso Cerqueira BA, Figueiredo CV, Santiago RP, da Guarda CC, Pitanga TN, Santana SS, Dias Zanette AM, Goncalves Mde S. Association of homocysteine and inflammatory-related molecules in sickle cell anemia. Hematology. 2016;21:126-31. Epub 2015/09/04.

26. Hebbel RP. Adhesion of sickle red cells to endothelium: myths and future directions. Transfusion clinique et biologique : journal de la Societe francaise de transfusion sanguine. 2008;15:14-8. Epub 2008/05/27.

27. Safaya $\mathrm{S}$, Steinberg $\mathrm{MH}$, Klings ES. Monocytes from sickle cell disease patients induce differential pulmonary endothelial gene expression via activation of NF-kappaB signaling pathway. Molecular immunology. 2012;50:117-23. Epub 2012/01/24.

28. Turhan A, Weiss LA, Mohandas N, Coller BS, Frenette PS. Primary role for adherent leukocytes in sickle cell vascular occlusion: a new paradigm. Proceedings of the National Academy of Sciences of the United States of America. 2002;99:3047-51. Epub 2002/03/07.

29. Ataga KI, Kutlar A, Kanter J, Liles D, Cancado R, Friedrisch J, Guthrie TH, Knight-Madden J, Alvarez OA, Gordeuk VR, Gualandro S, Colella MP, Smith WR, Rollins SA, Stocker JW, Rother RP. Crizanlizumab for the Prevention of Pain Crises in Sickle Cell Disease. The New England journal of medicine. 2017;376:429-39. Epub 2016/12/14.

30. Joneckis CC, Ackley RL, Orringer EP, Wayner EA, Parise LV. Integrin alpha 4 beta 1 and glycoprotein IV (CD36) are expressed on circulating reticulocytes in sickle cell anemia. Blood. 1993;82:3548-55. Epub 1993/12/15.

31. Sugihara K, Sugihara T, Mohandas N, Hebbel RP. Thrombospondin mediates adherence of CD36+ sickle reticulocytes to endothelial cells. Blood. 1992;80:2634-42. Epub 1992/11/15.

32. Swerlick RA, Eckman JR, Kumar A, Jeitler M, Wick TM. Alpha 4 beta 1-integrin expression on sickle reticulocytes: vascular cell adhesion molecule-1-dependent binding to endothelium. Blood. 1993;82:1891-9. Epub 1993/09/15.

33. Odievre $\mathrm{MH}$, Bony $\mathrm{V}$, Benkerrou $\mathrm{M}$, Lapoumeroulie $\mathrm{C}$, Alberti $\mathrm{C}$, Ducrocq $\mathrm{R}$, JacqzAigrain E, Elion J, Cartron JP. Modulation of erythroid adhesion receptor expression by 
hydroxyurea in children with sickle cell disease. Haematologica. 2008;93:502-10. Epub 2008/03/07.

34. Hoppe CC. Inflammatory mediators of endothelial injury in sickle cell disease. Hematology/oncology clinics of North America. 2014;28:265-86. Epub 2014/03/05.

35. Rother RP, Bell L, Hillmen P, Gladwin MT. The clinical sequelae of intravascular hemolysis and extracellular plasma hemoglobin: a novel mechanism of human disease. Jama. 2005;293:1653-62. Epub 2005/04/07.

36. Reiter CD, Wang X, Tanus-Santos JE, Hogg N, Cannon RO, 3rd, Schechter AN, Gladwin MT. Cell-free hemoglobin limits nitric oxide bioavailability in sickle-cell disease. Nature medicine. 2002;8:1383-9. Epub 2002/11/12.

*Important due to the in vivo characterization of toxic effects of hemoglobin in the intravascular hemolysis.

37. Rees DC, Gibson JS. Biomarkers in sickle cell disease. British journal of haematology. 2012;156:433-45. Epub 2011/11/30.

38. Camerer $\mathrm{E}, \mathrm{Kolsto} \mathrm{AB}$, Prydz $\mathrm{H}$. Cell biology of tissue factor, the principal initiator of blood coagulation. Thrombosis research. 1996;81:1-41. Epub 1996/01/01.

39. Mazzolai L, Silacci P, Bouzourene K, Daniel F, Brunner H, Hayoz D. Tissue factor activity is upregulated in human endothelial cells exposed to oscillatory shear stress. Thrombosis and haemostasis. 2002;87:1062-8. Epub 2002/06/27.

40. Solovey A, Kollander R, Shet A, Milbauer LC, Choong S, Panoskaltsis-Mortari A, Blazar BR, Kelm RJ, Jr., Hebbel RP. Endothelial cell expression of tissue factor in sickle mice is augmented by hypoxia/reoxygenation and inhibited by lovastatin. Blood. 2004;104:840-6. Epub 2004/04/10.

41. Feng C, Taiakina V, Ghosh DK, Guillemette JG, Tollin G. Intraprotein electron transfer between the FMN and heme domains in endothelial nitric oxide synthase holoenzyme. Biochimica et biophysica acta. 2011;1814:1997-2002. Epub 2011/08/26.

42. Busse R, Mulsch A. Calcium-dependent nitric oxide synthesis in endothelial cytosol is mediated by calmodulin. FEBS letters. 1990;265:133-6. Epub 1990/06/04.

43. Heller R, Munscher-Paulig F, Grabner R, Till U. L-Ascorbic acid potentiates nitric oxide synthesis in endothelial cells. The Journal of biological chemistry. 1999;274:8254-60. Epub 1999/03/13.

44. Dichtl W, Dulak J, Frick M, Alber HF, Schwarzacher SP, Ares MP, Nilsson J, Pachinger O, Weidinger F. HMG-COA reductase inhibitors regulate inflammatory transcription factors in human endothelial and vascular smooth muscle cells. Arteriosclerosis, thrombosis, and vascular biology. 2003;23:58-63. Epub 2003/01/14.

45. Semenza GL. Hypoxia-inducible factor 1: master regulator of $\mathrm{O} 2$ homeostasis. Current opinion in genetics \& development. 1998;8:588-94. Epub 1998/10/31.

46. Lok CN, Ponka P. Identification of a hypoxia response element in the transferrin receptor gene. The Journal of biological chemistry. 1999;274:24147-52. Epub 1999/08/14.

47. Tacchini L, Bianchi L, Bernelli-Zazzera A, Cairo G. Transferrin receptor induction by hypoxia. HIF-1-mediated transcriptional activation and cell-specific post-transcriptional regulation. The Journal of biological chemistry. 1999;274:24142-6. Epub 1999/08/14.

48. Lee PJ, Jiang BH, Chin BY, Iyer NV, Alam J, Semenza GL, Choi AM. Hypoxia-inducible factor-1 mediates transcriptional activation of the heme oxygenase-1 gene in response to hypoxia. The Journal of biological chemistry. 1997;272:5375-81. Epub 1997/02/28.

49. Zhang C, Zhang F. Iron homeostasis and tumorigenesis: molecular mechanisms and therapeutic opportunities. Protein \& cell. 2015;6:88-100. Epub 2014/12/06.

50. Smith A, Morgan WT. Haem transport to the liver by haemopexin. Receptor-mediated uptake with recycling of the protein. The Biochemical journal. 1979;182:47-54. Epub 1979/07/15. 
51. Wagener FA, Abraham NG, van Kooyk Y, de Witte T, Figdor CG. Heme-induced cell adhesion in the pathogenesis of sickle-cell disease and inflammation. Trends in pharmacological sciences. 2001;22:52-4. Epub 2001/02/13.

52. Almeida CB, Favero ME, Pereira-Cunha FG, Lorand-Metze I, Saad ST, Costa FF, Conran $\mathrm{N}$. Alterations in cell maturity and serum survival factors may modulate neutrophil numbers in sickle cell disease. Exp Biol Med (Maywood). 2011;236:1239-46. Epub 2011/10/15.

53. Bunn HF. Pathogenesis and treatment of sickle cell disease. The New England journal of medicine. 1997;337:762-9. Epub 1997/09/11.

54. Belcher JD, Marker PH, Weber JP, Hebbel RP, Vercellotti GM. Activated monocytes in sickle cell disease: potential role in the activation of vascular endothelium and vaso-occlusion. Blood. 2000;96:2451-9. Epub 2000/09/26.

55. Browne P, Shalev O, Hebbel RP. The molecular pathobiology of cell membrane iron: the sickle red cell as a model. Free radical biology \& medicine. 1998;24:1040-8. Epub 1998/06/02.

56. Pohl U, Lamontagne D. Impaired tissue perfusion after inhibition of endotheliumderived nitric oxide. Basic research in cardiology. 1991;86 Suppl 2:97-105. Epub 1991/01/01.

57. Roumenina LT, Rayes J, Lacroix-Desmazes S, Dimitrov JD. Heme: Modulator of Plasma Systems in Hemolytic Diseases. Trends in molecular medicine. 2016;22:200-13. Epub 2016/02/16.

58. Kumar S, Bandyopadhyay U. Free heme toxicity and its detoxification systems in human. Toxicology letters. 2005;157:175-88. Epub 2005/05/27.

59. Belcher JD, Beckman JD, Balla G, Balla J, Vercellotti G. Heme degradation and vascular injury. Antioxidants \& redox signaling. 2010;12:233-48. Epub 2009/08/25.

60. Jeney V, Balla J, Yachie A, Varga Z, Vercellotti GM, Eaton JW, Balla G. Pro-oxidant and cytotoxic effects of circulating heme. Blood. 2002;100:879-87. Epub 2002/07/20.

61. Santiago RP, Guarda CC, Figueiredo CVB, Fiuza LM, Adanho CSA, Aleluia MM, Zanette DL, Carvalho MOS, Lyra IM, Lopes VM, Nguyen J, Killeen T, Nguyen H, Vercellotti GM, Belcher JD, Goncalves MS. Serum Haptoglobin and Hemopexin Levels in Pediatric SS and SC Disease Patients: Biomarker of Hemolysis and Inflammation. Blood. 2016;128:3649-.

**Important due to the serum measurement of hemopexin and haptoglobin in patients with SCD, revealing decreased levels of these proteins.

62. Wagener FA, Eggert A, Boerman OC, Oyen WJ, Verhofstad A, Abraham NG, Adema G, van Kooyk $Y$, de Witte $T$, Figdor CG. Heme is a potent inducer of inflammation in mice and is counteracted by heme oxygenase. Blood. 2001;98:1802-11. Epub 2001/09/06.

63. Adisa OA, Hu Y, Ghosh S, Aryee D, Osunkwo I, Ofori-Acquah SF. Association between plasma free haem and incidence of vaso-occlusive episodes and acute chest syndrome in children with sickle cell disease. British journal of haematology. 2013;162:702-5. Epub 2013/06/28.

64. van Beers EJ, Yang Y, Raghavachari N, Tian X, Allen DT, Nichols JS, Mendelsohn L, Nekhai S, Gordeuk VR, Taylor JGt, Kato GJ. Iron, inflammation, and early death in adults with sickle cell disease. Circulation research. 2015;116:298-306. Epub 2014/11/08.

65. Korolnek T, Hamza I. Macrophages and iron trafficking at the birth and death of red cells. Blood. 2015;125:2893-7. Epub 2015/03/18.

66. Chiabrando D, Vinchi F, Fiorito V, Mercurio S, Tolosano E. Heme in pathophysiology: a matter of scavenging, metabolism and trafficking across cell membranes. Frontiers in pharmacology. 2014;5:61. Epub 2014/05/02.

67. Dutra FF, Alves LS, Rodrigues D, Fernandez PL, de Oliveira RB, Golenbock DT, Zamboni DS, Bozza MT. Hemolysis-induced lethality involves inflammasome activation by heme. Proceedings of the National Academy of Sciences of the United States of America. 2014;111:E4110-8. Epub 2014/09/17.

68. Aslan M, Ryan TM, Adler B, Townes TM, Parks DA, Thompson JA, Tousson A, Gladwin MT, Patel RP, Tarpey MM, Batinic-Haberle I, White CR, Freeman BA. Oxygen radical inhibition 
of nitric oxide-dependent vascular function in sickle cell disease. Proceedings of the National Academy of Sciences of the United States of America. 2001;98:15215-20. Epub 2001/12/26.

69. Nur E, Biemond BJ, Otten HM, Brandjes DP, Schnog JJ. Oxidative stress in sickle cell disease; pathophysiology and potential implications for disease management. American journal of hematology. 2011;86:484-9. Epub 2011/05/06.

70. Figueiredo RT, Fernandez PL, Mourao-Sa DS, Porto BN, Dutra FF, Alves LS, Oliveira MF, Oliveira PL, Graca-Souza AV, Bozza MT. Characterization of heme as activator of Toll-like receptor 4. The Journal of biological chemistry. 2007;282:20221-9. Epub 2007/05/16.

**Important because it was one of the first reports showing that heme was able to be an agonist of TLR.

71. Graca-Souza AV, Arruda MA, de Freitas MS, Barja-Fidalgo C, Oliveira PL. Neutrophil activation by heme: implications for inflammatory processes. Blood. 2002;99:4160-5. Epub 2002/05/16.

72. Wagener FA, Feldman E, de Witte T, Abraham NG. Heme induces the expression of adhesion molecules ICAM-1, VCAM-1, and E selectin in vascular endothelial cells. Proc Soc Exp Biol Med. 1997;216:456-63. Epub 1997/12/24.

**Important due to the evaluation of heme as a potent activator of vascular endothelial cells.

73. Monteiro AP, Pinheiro CS, Luna-Gomes T, Alves LR, Maya-Monteiro CM, Porto BN, Barja-Fidalgo C, Benjamim CF, Peters-Golden M, Bandeira-Melo C, Bozza MT, Canetti C. Leukotriene B4 mediates neutrophil migration induced by heme. J Immunol. 2011;186:6562-7. Epub 2011/05/04.

74. Arruda MA, Rossi AG, de Freitas MS, Barja-Fidalgo C, Graca-Souza AV. Heme inhibits human neutrophil apoptosis: involvement of phosphoinositide 3-kinase, MAPK, and NFkappaB. J Immunol. 2004;173:2023-30. Epub 2004/07/22.

75. O'Neill LA, Golenbock D, Bowie AG. The history of Toll-like receptors - redefining innate immunity. Nature reviews Immunology. 2013;13:453-60. Epub 2013/05/18.

76. Fortes GB, Alves LS, de Oliveira R, Dutra FF, Rodrigues D, Fernandez PL, Souto-Padron $T$, De Rosa MJ, Kelliher M, Golenbock D, Chan FK, Bozza MT. Heme induces programmed necrosis on macrophages through autocrine TNF and ROS production. Blood. 2012;119:236875. Epub 2012/01/21.

77. Pitanga TN, Oliveira RR, Zanette DL, Guarda CC, Santiago RP, Santana SS, Nascimento VM, Lima JB, Carvalho GQ, Maffili VV, Carvalho MO, Alcantara LC, Borges VM, Goncalves MS. Sickle red cells as danger signals on proinflammatory gene expression, leukotriene B4 and interleukin-1 beta production in peripheral blood mononuclear cell. Cytokine. 2016;83:75-84. Epub 2016/04/06.

78. da Guarda CC, Santiago RP, Pitanga TN, Santana SS, Zanette DL, Borges VM, Goncalves MS. Heme changes HIF-alpha, eNOS and nitrite production in HUVECs after simvastatin, HU, and ascorbic acid therapies. Microvascular research. 2016;106:128-36. Epub 2016/04/20.

79. Wang X, Mendelsohn L, Rogers H, Leitman S, Raghavachari N, Yang Y, Yau YY, Tallack M, Perkins A, Taylor JGt, Noguchi CT, Kato GJ. Heme-bound iron activates placenta growth factor in erythroid cells via erythroid Kruppel-like factor. Blood. 2014;124:946-54. Epub 2014/06/12.

80. Camus SM, De Moraes JA, Bonnin P, Abbyad P, Le Jeune S, Lionnet F, Loufrani L, Grimaud L, Lambry JC, Charue D, Kiger L, Renard JM, Larroque C, Le Clesiau H, Tedgui A, Bruneval P, Barja-Fidalgo C, Alexandrou A, Tharaux PL, Boulanger CM, Blanc-Brude OP. Circulating cell membrane microparticles transfer heme to endothelial cells and trigger vasoocclusions in sickle cell disease. Blood. 2015;125:3805-14. Epub 2015/04/02.

81. Charache S, Terrin ML, Moore RD, Dover GJ, Barton FB, Eckert SV, McMahon RP, Bonds DR. Effect of hydroxyurea on the frequency of painful crises in sickle cell anemia. Investigators 
of the Multicenter Study of Hydroxyurea in Sickle Cell Anemia. The New England journal of medicine. 1995;332:1317-22. Epub 1995/05/18.

82. Carvalho MOS, Rocha LC, Reis JHO, Santos TdA, do Nascimento VML, Carvalho MB, Luz NF, Borges VdM, Goncalves MS. Heme Concentration As a Biomarker of Sickle Cell Disease Severity: Its Role in Steady-State and in Crisis Patients. Blood. 2015;126:975-.

83. Schaer DJ, Buehler PW, Alayash AI, Belcher JD, Vercellotti GM. Hemolysis and free hemoglobin revisited: exploring hemoglobin and hemin scavengers as a novel class of therapeutic proteins. Blood. 2013;121:1276-84. Epub 2012/12/25.

84. Vercellotti GM, Zhang P, Nguyen J, Abdulla F, Chen C, Nguyen P, Nowotny C, Steer CS, Smith A, Belcher JD. Hepatic Overexpression of Hemopexin Inhibits Inflammation and Vascular Stasis in Murine Models of Sickle Cell Disease. Mol Med. 2016;22. Epub 2016/07/28. 
Figure 1. The vascular endothelium and irreversibly sickled erythrocyte interaction showing increased expression of adhesion molecules.

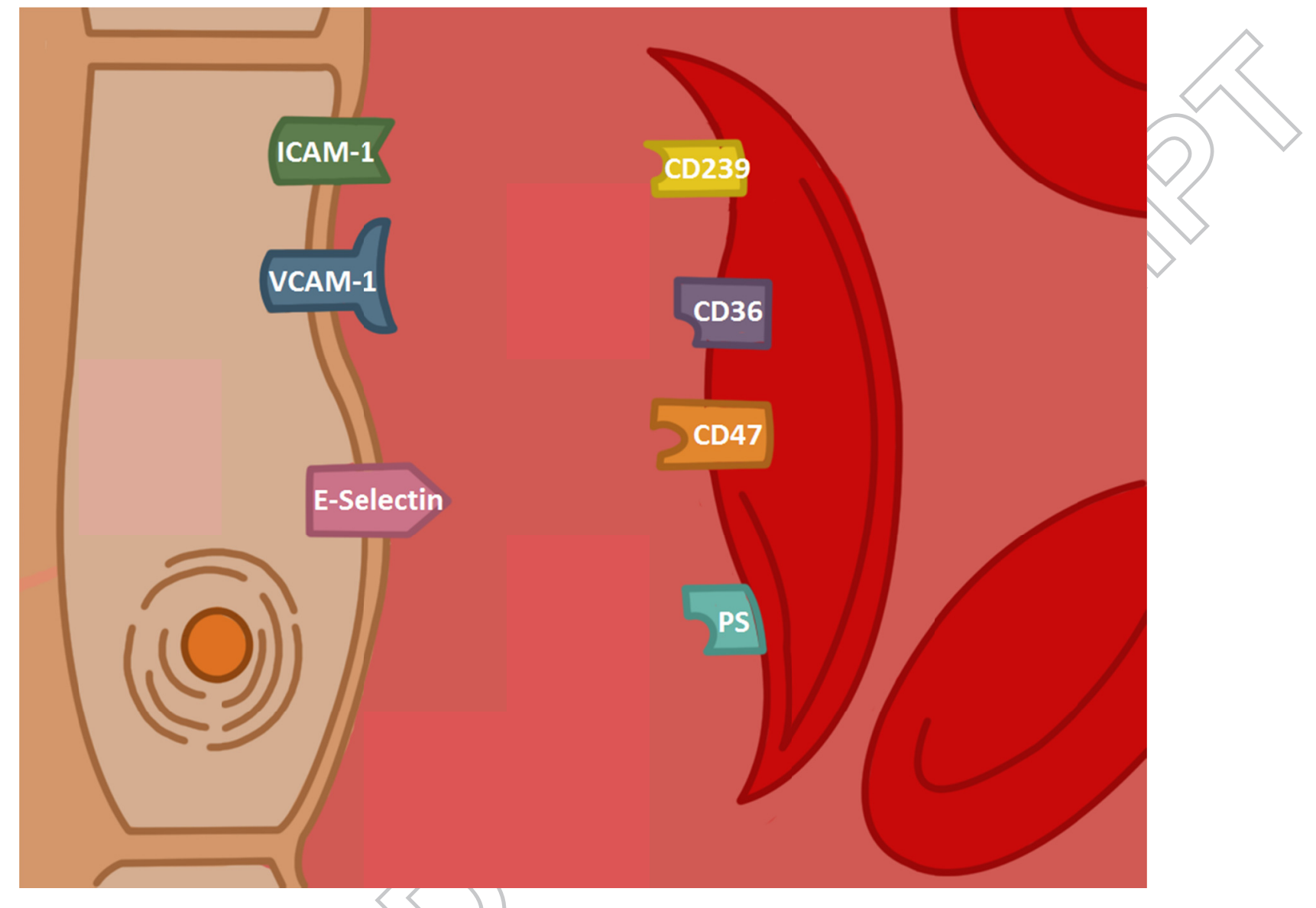


Figure 2. Illustration of a vaso-occlusive crisis in sickle cell anemia, emphasizing the participation of several blood cell types, including leukocytes, regular and irreversibly sickled erythrocytes, platelets, in addition to vascular endothelial cells that inhibit blood flow.
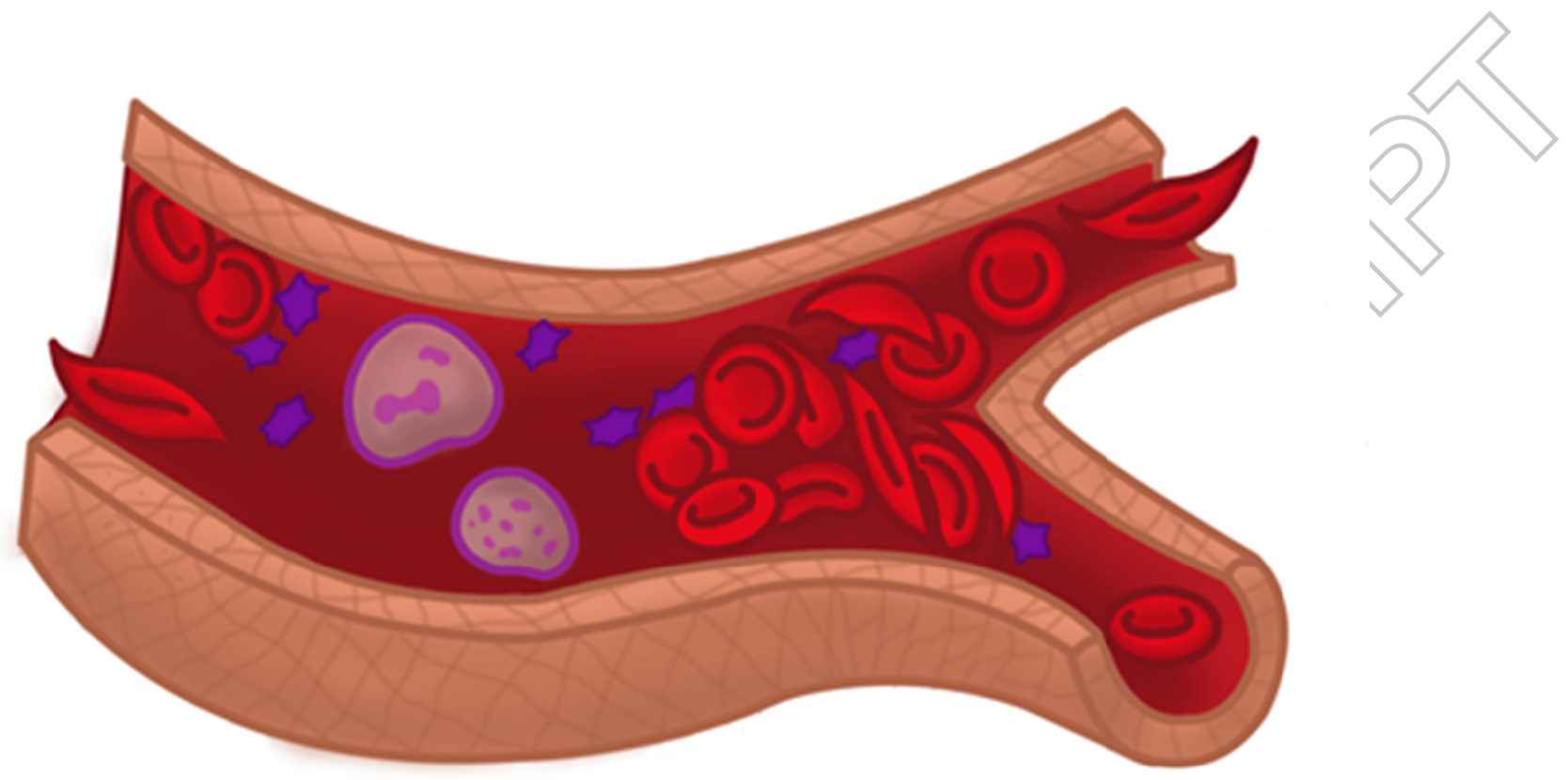
Figure 3. Scheme summarizing the cellular activation driven by heme on neutrophils, macrophages, monocytes and vascular endothelial cells in sickle
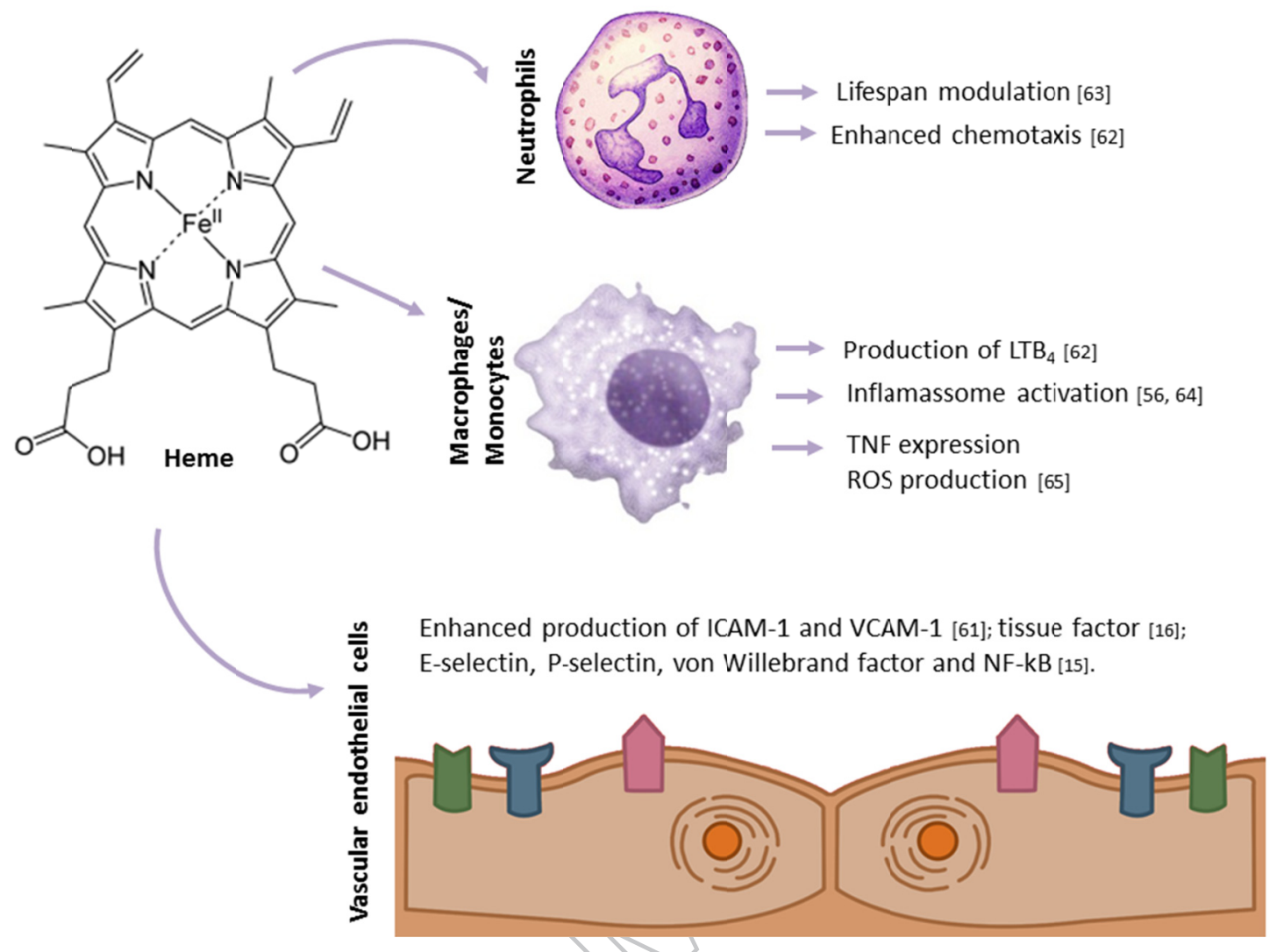